\title{
Cross-sectional associations of physical activity and gross motor proficiency with adiposity in South African children of pre-school age
}

\author{
Catherine E Draper ${ }^{1,2, *} \uparrow$, Simone A Tomaz ${ }^{1}$, Rachel A Jones ${ }^{3}$, Trina Hinkley ${ }^{4}$,
} Rhian Twine ${ }^{5}$, Kathleen Kahn ${ }^{5,6,7}$ and Shane A Norris ${ }^{2}$

'Division of Exercise Science and Sports Medicine, Department of Human Biology, University of Cape Town, Cape Town, South Africa: ${ }^{2}$ MRC/Wits Developmental Pathways for Health Research Unit, Faculty of Health Sciences, University of the Witwatersrand, Johannesburg, South Africa: ${ }^{3}$ Early Start, Faculty of Social Sciences, University of Wollongong, Wollongong, Australia: ${ }^{4}$ Institute for Physical Activity and Nutrition, School of Exercise and Nutrition Sciences, Deakin University, Geelong, Australia: ${ }^{5} \mathrm{MRC} /$ Wits Rural Public Health and Health Transitions Research Unit (Agincourt), School of Public Health, Faculty of Health Sciences, University of the Witwatersrand, Johannesburg, South Africa: ${ }^{6}$ Umeå Centre for Global Health Research, Umeå University, Umeå, Sweden: ${ }^{7}$ INDEPTH Network, Accra, Ghana

Submitted 3 May 2018: Final revision received 11 September 2018: Accepted 6 November 2018: First published online 26 December 2018

\begin{abstract}
Objective: The study aimed to investigate the relationship between physical activity, gross motor skills and adiposity in South African children of pre-school age.

Design: Cross-sectional study.

Setting: High-income urban, and low-income urban and rural settings in South Africa.

Participants: Children (3-6 years old, $n$ 268) were recruited from urban highincome ( $n$ 46), urban low-income ( $n$ 91) and rural low-income ( $n$ 122) settings. Height and weight were measured to calculate the main outcome variables: BMI and BMI-for-age $Z$-score (BAZ). Height-for-age and weight-for-age $Z$-scores were also calculated. Actigraph GT3X+ accelerometers were used to objectively measure physical activity; the Test of Gross Motor Development (Version 2) was used to assess gross motor skills.

Results: More children were overweight/obese and had a higher BAZ from urban low-income settings compared with urban high-income settings and rural lowincome settings. Being less physically active was associated with thinness, but not overweight/obesity. Time spent in physical activity at moderate and vigorous intensities was positively associated with BMI and BAZ. Gross motor proficiency was not associated with adiposity in this sample.

Conclusions: The findings of this research highlight the need for obesity prevention particularly in urban low-income settings, as well as the need to take into consideration the complexity of the relationship between adiposity, physical activity and gross motor skills in South African pre-school children.
\end{abstract}

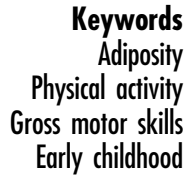

Concern about overweight and obesity in the pre-school years has increased globally in the last two decades ${ }^{(1)}$, with $76 \%$ of overweight children under the age of 5 years living in low- and middle-income countries ${ }^{(2)}$. In Africa, the estimated prevalence of overweight/obesity in 2015 was $10 \cdot 4 \%$ and is estimated to be $12 \cdot 7 \%$ by 2020 . Furthermore, the projected relative increase in overweight/ obesity from 2010 to 2020 is predicted to be substantially

$†$ Address for correspondence: Sports Science Institute of South Africa, Boundary Road, Newlands, Cape Town 7700, South Africa. higher in Africa than in high-income countries (49.4 and $20 \cdot 5 \%$, respectively) ${ }^{(1)}$. The various physical, psychosocial health and economic consequences of childhood obesity are well documented ${ }^{(3-5)}$, highlighting the importance of focusing on a number of key health behaviours of young children to prevent anticipated trends in obesity ${ }^{(1,2,6)}$.

In South Africa, 22.9\% of 2-5-year-old children were found to be overweight/obese in the 2013 South African National Health and Nutrition Examination Survey (SANHANES-1) ${ }^{(7)}$, with higher rates among girls compared with boys and in low-income urban settings compared 
with high-income settings. This rate of overweight/obesity is higher than in other nationally representative samples reported for sub-Saharan Africa (between 2.0 and $16.9 \%)^{(8)}$. Recent data from the Birth to Twenty cohort study in South Africa indicate that early childhood is a crucial period for predicting obesity in later adolescence $^{(9)}$. Girls who were obese at $4-8$ years were $42 \cdot 3$ times more likely to be obese at $16-18$ years. Boys who were obese at 4-8 years were 19.7 times more likely to be obese at 16-18 years ${ }^{(9)}$. Therefore, in the South African context, the pre-school years represent a critical period during the life course to prevent obesity.

Alongside the concerns regarding overweight/obesity in Africa, undernutrition continues to exist among young children, thus creating a double burden of over- and undernutrition. In sub-Saharan populations in particular, stunting is more prevalent than in high-income countries ${ }^{(10)}$. In South Africa, undernutrition is most prevalent in rural areas and is generally higher in boys than girls ${ }^{(7)}$. Although the prevalence of undernutrition among South African children is much lower than in other sub-Saharan countries $^{(11)}$, it is still higher than in developed countries and the fact that it still coexists with overnutrition is concerning.

Contributing to this double burden of over- and undernutrition in South Africa is the presence of gross income inequalities, as well as the legacy of historical apartheid policies that put certain urban and rural areas at an economic and social disadvantage. Although South Africa is classified as an upper middle-income country, according to the World Bank it is one of the most unequal societies in the world. The uppermost decile of the South African population accounts for almost $60 \%$ of South Africa's income, while the lowest decile accounts for less than $1 \%$. The World Bank has described the South African economy as a 'dual economy', defined as an economy where technically advanced and primitive sectors exist, serving to perpetuate inequality ${ }^{(12)}$.

A number of factors are associated with overweight/ obesity in early childhood. For example, higher levels of physical activity ${ }^{(13-17)}$ have been associated with favourable measures of adiposity, and poor gross motor skills have been associated with overweight/obesity in early ${ }^{(18)}$ and later childhood ${ }^{(19-21)}$. However, the relationship between weight status and gross motor skills has differed according to the types of skills assessed ${ }^{(22)}$.

While recent research has reported on these individual factors among South African pre-school children ${ }^{(23)}$, their relationship with over- and undernutrition has not yet been fully explored. For example, how this relationship might differ across settings and between boys and girls remains unknown. It is important to investigate these relationships further because over- and undernutrition differ according to geographical location ${ }^{(7,24)}$ and between boys and girls in early childhood. Further understanding of how physical activity and gross motor development are associated with overweight/obesity will be essential for the planning and evaluation of interventions to prevent and/or manage early childhood overweight/obesity in these settings.

Therefore, the aims of the present study conducted among South African children of pre-school age were to: (i) compare adiposity between settings and between boys and girls; (ii) determine associations of physical activity and gross motor skills with adiposity in urban and rural settings; and (iii) identify how these associations differ across settings. We hypothesised that children who spend less time in moderate- to vigorous-intensity physical and have lower levels of gross motor proficiency will fall outside the healthy range for adiposity outcomes.

\section{Methods}

The current paper presents a cross-sectional study conducted between 2012 and 2014, which was part of a broader programme of research in urban and rural South African settings. The study settings, sample and methods have been reported elsewhere ${ }^{(23)}$. Where necessary, specific methods are repeated or described in more detail below.

\section{Study settings}

Data were collected in three settings. The urban highincome and the urban low-income settings were based in Cape Town, South Africa (data collected in 2012). The high-income setting had a population density approximately fifteen times lower than that of the urban lowincome setting. The high-income area has a number of high-quality private and public schools, various private health facilities and services, public parks and green spaces, expensive retailers and well-serviced amenities. The urban low-income setting was a 'township', with common challenges in this community including overcrowding, crime, unemployment, alcohol abuse and a high rate of HIV/AIDS. The rural low-income setting was the Medical Research Council (MRC)/University of the Witwatersrand (Wits) Rural Public Health and Health Transitions Research Unit (Agincourt) study area (data collected in 2014), located in the north-east province of Mpumalanga. This unit has completed several research studies in the area but to date no studies have been completed with children of pre-school age. HIV/AIDS prevalence is high and unemployment is widespread in the area, with an estimated $60 \%$ of men and increasing numbers of women migrating to more urban areas for work ${ }^{(25,26)}$.

\section{Study sample and recruitment}

Children were recruited through pre-schools at all settings ( $n$ 268, mean age 5.17 (sD 0.70) years, $49.25 \%$ girls). The two urban low-income pre-schools were recruited using convenience sampling based on existing contacts. The urban high-income pre-school children were recruited by 
word of mouth and snowball sampling. In the rural lowincome setting, recruitment was coordinated through the MRC/Wits-Agincourt Unit's Public Engagement Office. All three pre-schools in one low-income rural village were recruited to participate in the study. The pre-schools (and pre-school children) invited to participate were intentionally diverse to ensure that they were as representative as possible, taking account of geographical location and socio-economic status at a community level.

\section{Data collection}

\section{Assessment of anthropometrics}

Children's height and weight were measured (shoes and heavy clothing removed) using a portable stadiometer (Leicester 214 Transportable Stadiometer; Seca GmbH \& Co., Hamburg, Germany) and a calibrated scale (Soehnle 7840 Mediscale Digital; Soehnle Industrial Solutions GmbH, Backnang, Germany), respectively. All measurements were taken twice, and an average taken of the two for analyses. Measurements taken at the time of gross motor skill testing are used for the purposes of the present paper.

Height and weight measurements were used to calculate BMI as an indicator for overall adiposity. The International Obesity Task Force (IOTF) ${ }^{(27)}$ cut-offs were used to classify children as thin, normal weight, overweight, obese and morbidly obese. BMI and $Z$-scores for BMI-for age (BAZ), height-for-age (HAZ) and weight-forage (WAZ) were computed using the WHO AnthroPlus software (http://www.who.int/growthref/tools/en/).

Assessment of physical activity and sedentary behaviour Actigraph GT3X + accelerometers (ActiGraph LLC, Pensacola, FL, USA) were used for the objective measurement of physical activity. The accelerometer was fitted to each child's right hip using an elasticated belt. Children wore the monitors for $24 \mathrm{~h} / \mathrm{d}$ over a $7 \mathrm{~d}$ period. ActiLife version 6 software (ActiGraph LLC) was used to manage the data. Physical activity data were collected within 2-4 weeks of the adiposity and gross motor skills measurement.

Participants' data were included if they had seven hours of valid waking wear-time (excluding sleep time) on each of three weekdays and one weekend day ${ }^{(28)}$. Data were recorded in $15 \mathrm{~s}$ epochs ${ }^{(29)}$. Non-wear time was defined as $20 \mathrm{~min}$ or more of consecutive zeroes and excluded $^{(30)}$. Cut-off points chosen to identify lightintensity physical activity (LPA) and moderate- to vigorous-intensity physical activity (MVPA) in the present study were $>25$ counts $/ 15 s^{(31)}$ and $>420$ counts/ $15 \mathrm{~s}^{(27)}$, respectively. Thus, total physical activity (referred to as light- and moderate- to vigorous-intensity physical activity, LMVPA hereafter) comprised physical activity of $>25$ counts $/ 15 \mathrm{~s}$. These cut-off points have been shown to accurately classify physical activity (and sedentary behaviour) in pre-school children ${ }^{(32)}$.
Assessment of gross motor skill proficiency

The Test for Gross Motor Development - Second Edition (TGMD-2) was used to assess gross motor skill proficiency (object control and locomotor skills). This is a valid and reliable criterion-norm referenced test for children aged 3 to 10 years ${ }^{(33)}$. Standard testing procedures were used, testing took place at the pre-school or a convenient location, and children were tested in groups (four to seven children in each group). Testing was video-recorded to allow for more accurate scoring ${ }^{(34)}$. TGMD-2 raw scores, standard scores (according to age and sex) and gross motor quotient (GMQ) scores were generated for each child. The urban and rural samples were scored by two separate individuals. The individual scoring the rural sample repeated the scoring for fourteen randomly selected TGMD-2 assessments (out of $n 137$ for the urban sample, $\pm 10 \%$ of the sample). Lin's concordance correlation coefficient ${ }^{(35)}$ was used to assess agreement between the sum of the raw locomotor scores as well as the object control scores for sets of data. Agreement between the two scorers was 0.88 (95\% CI 0.63, 0.99) and 0.74 (95\% CI $0.41,0.96$ ) for the locomotor and object control raw scores, respectively.

\section{Data analysis}

Anthropometric variables included in the analyses were BMI, BAZ, HAZ and WAZ, along with percentages of children in the IOTF weight status categories, with BMI and BAZ as the main outcome variables. Physical activity variables included average daily time spent in light-, moderate- and vigorousintensity physical activity (LPA, MPA and VPA, respectively), as well as LMVPA and MVPA. Gross motor skill variables included a measure of locomotor and object control raw scores, sum of raw scores, locomotor and object control standard scores, and overall gross motor proficiency (GMQ). Raw scores were used in the analyses to test associations.

All statistical analyses were carried out using the statistical software package Stata version 13 for Mac. Descriptive data are presented as mean and SD for normally distributed data, and as median and interquartile range for data not normally distributed. The percentages of children in the different IOTF weight status categories were calculated, as well as the percentages classified as thin (BAZ $<-2)$, stunted (HAZ $<-2)$, wasted (WAZ $<-2)$, and stunted and wasted, according to WHO criteria.

Differences between boys and girls were assessed using Student's unpaired $t$ test for normally distributed data and the Mann-Whitney $U$ test for data non-normally distributed data. Differences between settings were assessed using one-way ANOVA for normally distributed data and Kruskal-Wallis analysis for non-normally distributed data; where there were significant between-setting differences, the Bonferroni post hoc test and Mann-Whitney $U$ tests were used, respectively. Ordinal data were compared using $\chi^{2}$ tests.

Correlations were run to determine the relationship of BMI, BAZ, HAZ and WAZ with sum of raw scores, LMVPA, 
MVPA and VPA. Thereafter, variables defined a priori (sex, age, setting and gross motor skills), as well as physical activity correlates where $P<0 \cdot 05$ (excluding any collinear variables), were included in a linear hierarchal regression to determine factors independently associated with BAZ (as the adiposity outcome variable of choice). Model 1 included demographic and child-level factors, including age, sex and income setting. Model 2 included variables in model 1 plus the physical activity variable (LMVPA). Model 3 included gross motor skills (locomotor and object control raw scores) in addition to all variables in models 1 and 2 . Variables defined a priori were also used in a multinomial logistic regression analysis, which was performed to determine factors associated with the various IOTF categories, namely normal weight, thinness (degrees 1, 2 and 3) and overweight/obesity (inclusive of morbid obesity). Variables included in the multinomial logistic regression were age, sex, setting, locomotor and object control raw scores, and LMVPA.

\section{Results}

Complete adiposity data were available for 268 children, complete physical activity data were available for 229 children and complete gross motor data were available for 259 children.

\section{Differences according to setting and sex}

Age, BMI, weight status, BAZ, HAZ and WAZ of children are presented in Table 1 . The sample was predominantly (70-76\%) normal weight, and setting and IOTF weight status were significantly related $(P=0.001)$. There were significantly more overweight/obese children from the urban low-income setting (16.49\%) compared with the urban high-income and the rural low-income settings ( 4.35 and $4.92 \%$, respectively, $P=0.001$ for both). Children from the urban low-income setting also had significantly higher BMI and BAZ than those from the urban high-income $(P=0.001$ for both) and rural low-income $(P<0.001$ for both) settings. Children from the urban high-income setting had significantly higher HAZ compared with children from the urban and rural low-income settings $(P<0.001$ for both). There were no significant differences between settings for WAZ or for the prevalence of wasting and stunting (according to WHO criteria).

The data in Table 2 show that there were no significant differences between boys and girls for any adiposity variable. In the multinomial logistic regression model presented in Table 3, girls were more likely to be thin than boys $(P=0 \cdot 019)$.

\section{Associations between adiposity, physical activity and gross motor skills}

Table 3 presents data on gross motor skills and physical activity according to IOTF weight status categories.
Data presented according to sex and setting are included in the online supplementary material, Supplemental Tables 1 and 2, respectively. Mean LMVPA for the total sample was 460.38 (sD 65.66) min. Compared with children classified as thin, children who were normal weight engaged in more MPA $(P=0.012)$, VPA $(P=0 \cdot 029)$, MVPA $(P=0 \cdot 01)$ and LMVPA $(P=0.006)$, but not LPA (total sample).

In the correlation analyses with the total sample, there were weak but significant positive associations between BMI and BAZ and physical activity at all intensities (range: 0.1325-0.2023), except between LPA and BMI. These results are presented in the online supplementary material, Supplemental Table 3. When these associations were examined separately for each setting, no relationships were found between physical activity and any of the adiposity variables in the urban high-income sample. In the urban low-income sample, weak but significant positive associations were found between LPA and HAZ and WAZ, and between LMVPA and WAZ. In the rural low-income sample, weak but significant positive associations were found between BMI and BAZ and LMVPA, MVPA and VPA. Also in this sample, there were weak but significant negative associations between HAZ and LPA and LMVPA. These results are presented in Supplemental Tables 4-6.

For gross motor skills, there was only a weak but significant negative association between object control skills and BMI and BAZ in the urban low-income sample. In the multinomial logistic regression analysis, a higher object control raw score was associated with thinness $(P=0 \cdot 019)$.

In the hierarchical regression model shown in Table 4 , in the final model 3 (including age, sex, setting, LMVPA, locomotor raw score and object control raw score), only the urban low-income setting was found to be associated with a higher BAZ $(P=0 \cdot 007)$. Sex (female) approached significance $(P=0.059)$ for a lower BAZ. In model 2 of the hierarchical regression model (locomotor and object control raw scores excluded), LMVPA was significantly associated with a higher BAZ $(P=0.033)$ although the coefficient was very low $(\beta=-0 \cdot 002)$. But this lost significance $(P=0.054)$ when locomotor and object control raw scores were included in the model. Model 1 explained $8 \%$ of the variance in $\mathrm{BAZ}$ ( $n$ 268, $R^{2}=0 \cdot 08, P<0 \cdot 000$ ); model 2, $10 \%$ ( $n$ 229, $\left.R^{2}=0 \cdot 10, P<0 \cdot 000\right)$; and model 3, $12 \%$ of the variance $\left(n 220, R^{2}=0 \cdot 12, P<0 \cdot 000\right)$.

In the multinomial logistic regression analysis (total sample, Table 5), LMVPA was significantly negatively associated with thinness $(P=0 \cdot 022)$. Being classified as overweight or obese was not associated with physical activity at any intensity.

\section{Discussion}

The current paper presents novel findings on the relationship between adiposity, physical activity and gross motor 
Table 1 Adiposity variables for South African children of pre-school age from urban high-income, urban low-income and rural low-income settings, 2012-2014

\begin{tabular}{|c|c|c|c|c|c|c|c|c|c|c|c|c|c|c|c|c|c|}
\hline & \multicolumn{4}{|c|}{ Total $(n$ 268) } & \multicolumn{4}{|c|}{ Urban high-income ( $n$ 46) } & \multicolumn{4}{|c|}{ Urban low-income ( $n$ 91) } & \multicolumn{4}{|c|}{ Rural low-income ( $n$ 131) } & \multirow[b]{2}{*}{$P$ value } \\
\hline & Mean & SD & Median & IQR & Mean & SD & Median & IQR & Mean & SD & Median & IQR & Mean & SD & Median & IQR & \\
\hline Age (years) & $5 \cdot 17$ & 0.70 & $5 \cdot 21$ & $4.67-5.75$ & $5 \cdot 28$ & 0.72 & $5 \cdot 25$ & $4.83-5.67$ & $5 \cdot 35$ & 0.72 & 5.50 & $4.92-5.83$ & 5.02 & 0.64 & $5 \cdot 00$ & $4 \cdot 5-5 \cdot 58$ & 0.001 \\
\hline $\mathrm{BMI}\left(\mathrm{kg} / \mathrm{m}^{2}\right)$ & 15.45 & 1.55 & $15 \cdot 35$ & $14.35-16 \cdot 24$ & 15.02 & 1.11 & 14.98 & $14.27-15.77$ & 16.00 & $1 \cdot 71$ & $15 \cdot 73$ & $14.87-16.86$ & $15 \cdot 22$ & 1.50 & $15 \cdot 17$ & $14.16-16.07$ & 0.000 \\
\hline & -0.04 & 1.03 & -0.04 & $-0.67-0.69$ & -0.25 & 0.81 & -0.24 & $-0.86-0.37$ & 0.40 & 1.05 & 0.37 & $-0.30-1.00$ & -0.10 & 1.02 & -0.06 & $-0.79-0.54$ & 0.000 \\
\hline $\mathrm{HAZ}$ & -0.25 & 1.02 & -0.23 & $-1.02-0.50$ & 0.34 & 0.95 & 0.34 & $-0.17-0.91$ & -0.43 & 0.99 & -0.38 & $-1.15-0.25$ & -0.39 & 0.98 & -0.45 & $-1.12-0.45$ & 0.000 \\
\hline WAZ & -0.12 & 1.01 & -0.19 & $-0.76-0.61$ & 0.05 & 0.92 & $0 \cdot 10$ & $-0.51-0.69$ & 0.00 & $1 \cdot 12$ & -0.02 & $-0.79-0.89$ & -0.30 & 0.94 & -0.40 & $-0.86-0.40$ & 0.061 \\
\hline \multicolumn{18}{|l|}{ WHO criteria } \\
\hline Thinness (\%) & & & 1.49 & & & & 0.00 & & & & 0.00 & & & & 3.28 & & 0.120 \\
\hline Stunting (\%) & & & $4 \cdot 10$ & & & & 0.00 & & & & 5.50 & & & & 4.92 & & 0.389 \\
\hline Wasting (\%) & & & 3.36 & & & & $2 \cdot 17$ & & & & $4 \cdot 40$ & & & & 3.28 & & 0.764 \\
\hline Stunting \& wasting (\%) & & & 1.49 & & & & 0.00 & & & & $2 \cdot 20$ & & & & 1.64 & & 0.605 \\
\hline \multicolumn{18}{|l|}{ IOTF categories } \\
\hline Thinness (\%) & & & $19 \cdot 40$ & & & & 23.91 & & & & $7 \cdot 69$ & & & & $25 \cdot 41$ & & 0.001 \\
\hline Normal weight (\%) & & & 71.64 & & & & 71.74 & & & & $75 \cdot 82$ & & & & 69.67 & & \\
\hline Overweight (\%) & & & 5.97 & & & & 4.35 & & & & 10.99 & & & & 2.46 & & \\
\hline Obesity \& morbid obesity (\%) & & & 2.99 & & & & 0.00 & & & & $5 \cdot 50$ & & & & $2 \cdot 46$ & & \\
\hline
\end{tabular}

IQR, interquartile range; BAZ, BMI-for-age Z-score; HAZ, height-for-age Z-score; WAZ, weight-for-age Z-score; IOTF, International Obesity Task Force.

$P$ values shown for differences between settings using one-way ANOVA and Kruskal-Wallis analyses and $X^{2}$ analyses $(P<0.05$ indicates significance).

Table 2 Adiposity variables for South African children of pre-school age, according to sex, 2012-2014

\begin{tabular}{|c|c|c|c|c|c|c|c|c|c|c|c|c|c|}
\hline & \multicolumn{4}{|c|}{ Total $(n 268)$} & \multicolumn{4}{|c|}{ Boys ( $n$ 136) } & \multicolumn{4}{|c|}{ Girls ( $n$ 132) } & \multirow[b]{2}{*}{$P$ value } \\
\hline & Mean & SD & Median & IQR & Mean & SD & Median & IQR & Mean & SD & Median & IQR & \\
\hline Age (years) & 5.17 & 0.70 & $5 \cdot 21$ & $4.67-5.75$ & 5.24 & 0.74 & $5 \cdot 29$ & $4.67-5.79$ & $5 \cdot 10$ & 0.65 & 5.08 & $4.67-5.67$ & 0.143 \\
\hline $\mathrm{BMI}\left(\mathrm{kg} / \mathrm{m}^{2}\right)$ & $15 \cdot 45$ & 1.55 & $15 \cdot 35$ & $14 \cdot 35-16 \cdot 24$ & $15 \cdot 55$ & 1.35 & 15.45 & $14 \cdot 75-16 \cdot 27$ & $15 \cdot 35$ & 1.73 & $15 \cdot 12$ & $14 \cdot 18-16 \cdot 22$ & 0.069 \\
\hline$B A Z$ & -0.04 & 1.03 & 0.04 & $-0.67-0.69$ & 0.12 & 0.99 & 0.12 & $-0.42-0.73$ & -0.04 & 1.07 & 0.10 & $-0.77-0.61$ & 0.106 \\
\hline HAZ & -0.25 & 1.02 & -0.23 & $-1.02-0.50$ & -0.26 & 0.98 & -0.32 & $-0.98-0.54$ & -0.24 & 1.05 & -0.08 & $1.05-0.46$ & 0.881 \\
\hline WAZ & -0.12 & 1.01 & -0.19 & $-0.76-0.61$ & -0.07 & 0.89 & -0.11 & $-0.71-0.58$ & -0.17 & 1.12 & -0.24 & $-0.90-0.66$ & 0.438 \\
\hline \multicolumn{14}{|l|}{ WHO criteria } \\
\hline Thinness (\%) & & & 1.49 & & & & 1.47 & & & & 1.52 & & 0.976 \\
\hline Stunting (\%) & & & $4 \cdot 10$ & & & & 2.94 & & & & $5 \cdot 31$ & & 0.465 \\
\hline Wasting (\%) & & & 3.36 & & & & $2 \cdot 26$ & & & & 4.55 & & 0.288 \\
\hline Stunting \& wasting (\%) & & & 1.49 & & & & 0.74 & & & & $2 \cdot 27$ & & 0.299 \\
\hline \multicolumn{14}{|l|}{ IOTF category } \\
\hline Thinness (\%) & & & $19 \cdot 40$ & & & & $16 \cdot 18$ & & & & $22 \cdot 72$ & & 0.205 \\
\hline Normal weight (\%) & & & 71.64 & & & & 76.47 & & & & 66.67 & & \\
\hline Overweight (\%) & & & 5.97 & & & & $5 \cdot 88$ & & & & 6.06 & & \\
\hline Obesity \& morbid obesity (\%) & & & 2.99 & & & & 1.47 & & & & 4.55 & & \\
\hline
\end{tabular}


Table 3 Gross motor skills and physical activity in South African children of pre-school age presenting with normal weight, thinness and overweight/obesity (IOTF categories), 2012-2014

\begin{tabular}{|c|c|c|c|c|c|c|c|c|c|c|c|c|c|}
\hline & \multicolumn{4}{|c|}{ Normal weight ( $n$ 187) } & \multicolumn{4}{|c|}{ Thinness ( $n$ 49) } & \multicolumn{4}{|c|}{ Overweight/obese (n 23) } & \multirow[b]{2}{*}{$P$ value } \\
\hline & Mean & SD & Median & IQR & Mean & SD & Median & IQR & Mean & SD & Median & IQR & \\
\hline \multicolumn{14}{|l|}{ TGMD-2 variables } \\
\hline Locomotor raw score & 35.89 & $6 \cdot 21$ & 37 & $33-41$ & 34.53 & $6 \cdot 91$ & 36 & $32-39$ & 34.87 & $6 \cdot 11$ & 37 & $32-39$ & 0.307 \\
\hline Object control raw score & 29.83 & 5.54 & 30 & $26-33$ & 30.29 & $6 \cdot 27$ & 30 & $26-35$ & $29 \cdot 87$ & $5 \cdot 32$ & 29 & $26-34$ & 0.831 \\
\hline Locomotor standard score & 11.41 & 2.47 & 11 & $10-13$ & $10 \cdot 96$ & 2.66 & 11 & $9-13$ & 11.22 & 2.39 & 12 & $10-13$ & 0.488 \\
\hline Object control standard score & $10 \cdot 43$ & $2 \cdot 17$ & 10 & $9-12$ & 11.02 & 2.73 & 11 & $9-12$ & $10 \cdot 74$ & 1.76 & 10 & $9-12$ & 0.414 \\
\hline Gross motor quotient & $105 \cdot 47$ & 11.69 & 106 & $97-115$ & $106 \cdot 06$ & $13 \cdot 20$ & 106 & $97-112$ & $104 \cdot 43$ & $12 \cdot 40$ & 106 & $100-112$ & 0.877 \\
\hline Physical activity variables & & & $(n 161)$ & & & & $(n 50)$ & & & & $(n+18)$ & & \\
\hline LPA & 340.95 & 43.50 & 343.4 & $318-366 \cdot 3$ & $327 \cdot 27$ & $40 \cdot 89$ & $326 \cdot 2$ & $299 \cdot 1-353 \cdot 3$ & 336.66 & 41.42 & 343.7 & $306 \cdot 6-369 \cdot 8$ & $0 \cdot 106$ \\
\hline MPA & 93.73 & 24.98 & 93.5 & $76 \cdot 3-110 \cdot 4$ & $82 \cdot 11$ & 21.56 & 83.0 & $68 \cdot 2-96 \cdot 1$ & $85 \cdot 34$ & $26 \cdot 38$ & $80 \cdot 1$ & $68 \cdot 9-103 \cdot 3$ & 0.012 \\
\hline VPA & 34.06 & $16 \cdot 43$ & $32 \cdot 4$ & $23 \cdot 3-42 \cdot 5$ & 27.88 & 11.98 & $28 \cdot 3$ & $18 \cdot 0-34.7$ & 28.04 & $17 \cdot 12$ & $27 \cdot 0$ & $16 \cdot 7-30 \cdot 4$ & 0.029 \\
\hline MVPA & $127 \cdot 78$ & 38.84 & $125 \cdot 9$ & $99 \cdot 9-151 \cdot 3$ & 109.98 & $30 \cdot 33$ & 113.4 & $85 \cdot 8-132 \cdot 6$ & 113.37 & 40.69 & $106 \cdot 2$ & $87 \cdot 6-133 \cdot 8$ & 0.010 \\
\hline LMVPA & 468.73 & 65.53 & 469.5 & $427 \cdot 3-511 \cdot 8$ & 437.24 & 58.44 & 427.7 & $399 \cdot 1-481 \cdot 2$ & 450.04 & $72 \cdot 18$ & $455 \cdot 8$ & $396.3-515.9$ & 0.006 \\
\hline
\end{tabular}

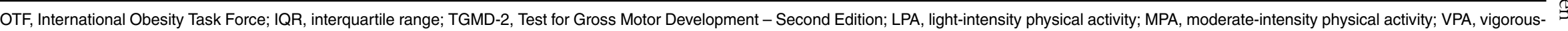
intensity physical activity; MVPA, moderate- to vigorous-intensity physical activity; LMVPA, light- and moderate- to vigorous-intensity physical activity.

Thinness is inclusive of degrees 1,2 and 3 . Overweight/obesity includes morbid obesity.

$P$ values shown for differences between IOTF categories using $X^{2}$ analyses $(P<0.05$ indicates significance)

Table 4 Summary of hierarchical regression model showing variables associated with BMI-for-age $Z$ score in South African children of pre-school age, $2012-2014$

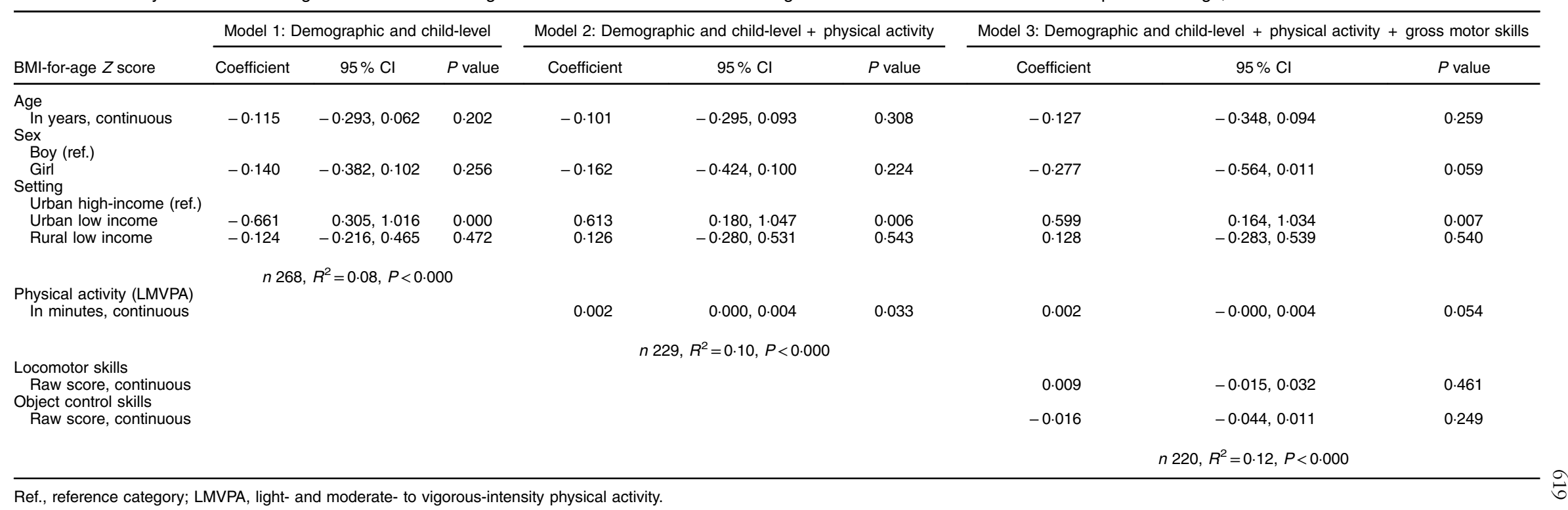

Ref., reference category; LMVPA, light- and moderate- to vigorous-intensity physical activity. 
Table 5 Summary of multinomial logistic regression model showing variables associated with thinness and overweight/obesity in South African children of pre-school age, 2012-2014

\begin{tabular}{|c|c|c|c|}
\hline IOTF category & Coefficient & $95 \% \mathrm{Cl}$ & $P$ value \\
\hline \multicolumn{4}{|l|}{ Thinness ( $v$. normal weight) } \\
\hline $\begin{array}{l}\text { Age } \\
\text { In years, continuous }\end{array}$ & -0.299 & $-0.889,0.292$ & 0.321 \\
\hline \multicolumn{4}{|l|}{ Sex } \\
\hline \multicolumn{4}{|l|}{ Boy (ref.) } \\
\hline Girl & 0.939 & $0.157,1.721$ & 0.019 \\
\hline \multicolumn{4}{|l|}{ Setting } \\
\hline \multicolumn{4}{|l|}{ Urban high-income (ref.) } \\
\hline Urban low-income & -0.521 & $-0.719,0.677$ & 0.394 \\
\hline Rural low-income & 0.301 & $-0.685,1.287$ & 0.550 \\
\hline \multicolumn{4}{|l|}{ Locomotor skills } \\
\hline Raw score, continuous & -0.017 & $-0.078,0.043$ & 0.578 \\
\hline \multicolumn{4}{|l|}{ Object control skills } \\
\hline Raw score, continuous & 0.086 & $0.014,0.159$ & 0.019 \\
\hline \multicolumn{4}{|l|}{ Physical activity (LMVPA) } \\
\hline In minutes, continuous & -0.007 & $-4.025,3.868$ & 0.022 \\
\hline \multicolumn{4}{|c|}{ Overweight/obese ( $v$. normal weight) } \\
\hline \multicolumn{4}{|l|}{ Age } \\
\hline In years, continuous & -0.300 & $-1 \cdot 153,0.554$ & 0.491 \\
\hline \multirow{2}{*}{\multicolumn{4}{|c|}{$\begin{array}{l}\text { Sex } \\
\text { Boy (ref) }\end{array}$}} \\
\hline Boy (ref.) & & & \\
\hline Girl & 0.937 & $-0.216,2.091$ & 0.111 \\
\hline \multicolumn{4}{|l|}{ Setting } \\
\hline \multicolumn{4}{|l|}{ Urban high-income (ref.) } \\
\hline Urban low-income & 2.003 & $-0.229,4.237$ & 0.079 \\
\hline Rural low-income & 0.839 & $-1.414,3.091$ & 0.465 \\
\hline \multicolumn{4}{|l|}{ Locomotor skills } \\
\hline Raw score, continuous & -0.008 & $-0.100,0.083$ & 0.858 \\
\hline \multicolumn{4}{|l|}{ Object control skills } \\
\hline Raw score, continuous & 0.090 & $-0.026,0.206$ & 0.129 \\
\hline \multicolumn{4}{|l|}{ Physical activity (LMVPA) } \\
\hline In minutes, continuous & 0.006 & $-0.015,0.002$ & 0.156 \\
\hline \multicolumn{4}{|c|}{ LR $X^{2}=32.96, P=0.003$, Pseudo $R^{2}=0.10$} \\
\hline
\end{tabular}

Ref., reference category; IOTF, International Obesity Task Force; LMVPA, lightand moderate- to vigorous-intensity physical activity; LR, likelihood ratio.

skills in children of pre-school age from a range of South African settings. The study responds, to some extent, to the call for more research to explore associations between adiposity and physical activity in settings undergoing epidemiological and nutrition transition where coexisting over- and undernutrition is a concern, since this may impact on other aspects of early childhood development $^{(36)}$.

In the present study the levels of overweight and obesity were lower than those found in the SANHANES- $1^{(7)}$. However, similar to SANHANES- ${ }^{(7)}$, the study findings showed that pre-school children from urban low-income settings had higher overweight/obesity levels and a higher BAZ compared with children in the other settings. These results can be explained by the rate of the epidemiological and nutrition transition in urban low-income settings ${ }^{(37)}$, the obesogenic characteristics of urban lowincome settings, such as the accessibility of cheap convenience foods, and lower levels of physical activity ${ }^{(38)}$. Furthermore, research indicates that, compared with populations in other settings, the urban poor are disproportionately affected by non-communicable diseases in South Africa ${ }^{(39)}$. Since early childhood obesity has been shown to be a strong predictor of obesity in later adolescence for children living in urban low-income settings in South Africa ${ }^{(9)}$, the findings of the current study highlight the need to prioritise these settings for obesity prevention strategies.

In terms of undernutrition, the absence of associations between thinness and settings and sex in the present study is contrary to data reported in the SANHANES-1, which found that undernutrition is more prevalent in rural areas and among boys ${ }^{(7)}$. However, the present findings confirm that low-income communities in South Africa contend with the double burden of over- and undernutrition, and that young children in these settings continue to be exposed to factors that compromise their longitudinal growth, as indicated by their significantly lower HAZ. These factors could include poor dietary diversity ${ }^{(40)}$ and food insecurity ${ }^{(41)}$.

In the current study, children who spent less time in MPA, VPA and MVPA were more likely to be classified as thin, compared with normal-weight children. Children participating in less LMVPA were found to be more likely to be thin. This is similar to previous research with urban South African pre-school children from a range of income settings, which found that underweight children were less likely to be active in the pre-school setting ${ }^{(42)}$. These findings highlight the possibility that young children with undernutrition have an energy deficit that may make them less likely to engage in physical activity. Furthermore, promoting higher levels of physical activity in children with energy deficits could potentially have negative consequences $^{(36)}$. It is therefore possible that in lowincome settings where children have energy deficits due to poor nutrition (e.g. poor dietary diversity and food insecurity, as mentioned above), interventions to improve nutrition may be of a higher priority than those focused on physical activity.

Further to this, the positive association between physical activity at higher intensities and BMI and BAZ also suggests that children who were more active at higher intensities had a BMI in the healthy range, compared with children with a BMI outside the healthy range (in both directions). However, while these associations were present in the overall sample, they were absent when examined in the urban high-income and low-income samples, but largely remained in the rural low-income sample. The positive relationship between physical activity and BMI found in the present study does not align with previous research showing an inverse relationship between physical activity and $\mathrm{BMI}^{(17)}$, and that overweight/obesity is associated with lower levels of physical activity $^{(13,15,16,43)}$. Also contrary to previous research ${ }^{(18,22)}$ was the finding that gross motor skills were not associated with overweight/obesity. Only a weak relationship was observed between BMI and BAZ and object control skills in urban low-income children. A possible explanation for 
this finding is the generally high level of gross motor skills in the study sample.

These findings therefore confirm our hypothesis for the relationship between physical activity and adiposity, at least in the direction of undernutrition, and more so for children of pre-school age in rural low-income settings. These findings all point to the possibility that the relationship between physical activity (perhaps at lighter intensities) and adiposity in low-income South African settings is more complex than previously found in other population groups. This includes the relationship between object control skills and thinness (logistic regression results); the indirect effect of LMVPA on the relationship between setting and BAZ (hierarchical regression results); and associations of LPA and LMVPA with HAZ and WAZ (some in the opposite direction to what would be expected). It is also possible that overall high levels of physical activity (>400 min LMVPA/d) and limited variance in these data among African preschool children ${ }^{(23)}$ may make it difficult to identify associations.

The limitations of the present study include the somewhat different methods used for recruitment in each setting, and relatively small sample sizes that were not randomly selected, which may have contributed to the absence of identified associations and differences between findings in this and other studies. This is particularly relevant in the urban high-income setting, where recruitment proved to be far more challenging than in the low-income settings. The time between data collection in the urban and rural sites is also a limitation, as well as the slight time delay (up to 4 weeks) between collecting anthropometric and accelerometry data. A strength of the study is that it presents findings from different regions in South Africa, although future research would be necessary to identify the extent to which similar results would be found in other urban and rural South African settings. This could impact on the selection of strategies to address over- and undernutrition in pre-school children from different settings, which may have access to different resources.

\section{Conclusion}

Understanding the relationship between adiposity, physical activity and gross motor skills in diverse settings is important for the development of initiatives to influence any of these outcomes ${ }^{(36)}$. In South Africa, interventions to address these outcomes in the context of obesity prevention have not been developed and evaluated systematically ${ }^{(44)}$. The findings of the present research highlight the need for obesity prevention particularly in urban low-income settings, as well as the need to take into consideration the complexity of the relationship between the outcomes mentioned above in transitioning low- and middle-income country settings where there is a double burden of coexisting over- and undernutrition. This could mean that increased energy expenditure through physical activity may receive less emphasis in these settings and that the focus of obesity prevention should relate to healthy nutrition. This includes healthier dietary choices, but also strategies that address the food environment and environmental factors that impact on dietary choices. This is particularly relevant in low- and middle-income country settings, in Africa especially, that have growing low-income urban populations. Future research should evaluate the extent to which environmental interventions can mitigate obesity risk in early childhood.

\section{Acknowledgements}

Acknowledgements: The authors would like to thank local fieldworkers Vivian Nzima, Rose Mnisi and Nandipha Sinyana. They would also like to thank all pre-schools who participated in this research, as well as the MRC/ Wits-Agincourt Research Unit for facilitating research in Agincourt (supported by the University of the Witwatersrand, the South African Medical Research Council and the Wellcome Trust, UK (grant numbers 058893/Z/99/A; 069683/Z/02/Z; 085477/Z/08/Z; 085477/B/08/Z)). The authors also acknowledge previous students involved in collecting data presented in this paper: Sheri-Lee Bernstein and Lesala Mampa. Financial support: Funding support for this research was received from the SA National Research Foundation (grant number CPRR13090934186) and the University of Cape Town University Research Committee. For S.A.T., the support of the DST-NRF Centre of Excellence in Human Development at the University of the Witwatersrand, Johannesburg, Republic of South Africa towards this research is hereby acknowledged. The opinions expressed, and conclusions arrived at, are those of the authors and are not to be attributed to the Centre of Excellence in Human Development. T.H. is funded by a National Health and Medical Research Council Early Career Fellowship (grant number APP1070571). Conflict of interest: The authors have no conflicts of interest to declare. Authorship: C.E.D. and S.A.N. conceptualised the study. S.A.T. completed part of the data collection as part of her PhD (C.E.D. main supervisor, R.A.J. and T.H. co-supervisors) and conducted the statistical analyses. K.K. and R.T. facilitated the rural component of the research. C.E.D and S.A.T drafted the manuscript, C.E.D. was responsible for revisions to the manuscript; all authors commented on the manuscript and approved the final version. Ethics of human subject participation: This study was conducted according to the guidelines laid down in the Declaration of Helsinki and all procedures involving human subjects/patients were approved by the University of Cape Town Human Research Ethics Committee (HREC REF 
237/2012), the University of the Witwatersrand Human Research Ethics Committee (Medical) (M140250) and the Mpumalanga Provincial Departments of Health and Education. Written informed parental consent was obtained for all children who participated in the study.

\section{Supplementary material}

To view supplementary material for this article, please visit https://doi.org/10.1017/S1368980018003579

\section{References}

1. de Onis M, Blossner M \& Borghi E (2010) Global prevalence and trends of overweight and obesity among preschool children. Am J Clin Nutr 92, 1257-1264.

2. Black RE, Victora CG, Walker SP et al. (2013) Maternal and child undernutrition and overweight in low-income and middle-income countries. Lancet 382, 427-451.

3. Ebbeling CB, Pawlak DB \& Ludwig DS (2002) Childhood obesity: public-health crisis, common sense cure. Lancet 360, 473-482.

4. Lobstein T, Baur L, Uauy R et al. (2004) Obesity in children and young people: a crisis in public health. Obes Rev $\mathbf{5}$, Suppl. 1, 4-104.

5. Reilly JJ, Methven E, McDowell ZC et al. (2003) Health consequences of obesity. Arch Dis Child 88, 748-752.

6. Reilly JJ (2008) Physical activity, sedentary behaviour and energy balance in the preschool child: opportunities for early obesity prevention. Proc Nutr Soc 67, 317-325.

7. Shisana O, Labadarios D, Rehle T et al. (2013) South African National Health and Nutrition Examination Survey (SANHANES-1). Cape Town: HSRC Press.

8. Gebremedhin S (2015) Prevalence and differentials of overweight and obesity in preschool children in SubSaharan Africa. BMJ Open 5, e009005.

9. Lundeen EA, Norris SA, Adair LS et al. (2016) Sex differences in obesity incidence: 20-year prospective cohort in South Africa. Pediatr Obes 11, 75-80.

10. de Onis M, Blössner M \& Borghi E (2012) Prevalence and trends of stunting among pre-school children, 1990-2020. Public Health Nutr 15, 142-148.

11. Akombi BJ, Agho KE, Merom D et al. (2017) Child malnutrition in sub-Saharan Africa: a meta-analysis of demographic and health surveys (2006-2016). PLoS One 12, e0177338.

12. The World Bank (2018) Overview: South Africa. http:// www.worldbank.org/en/country/southafrica/overview (accessed August 2018).

13. te Velde SJ, van Nassau F, Uijtdewilligen L et al. (2012) Energy balance-related behaviours associated with overweight and obesity in preschool children: a systematic review of prospective studies. Obes Rev 13, Suppl. 1, 56-74.

14. Byun W, Dowda M \& Pate RR (2011) Correlates of objectively measured sedentary behavior in US preschool children. Pediatrics 128, 937-945.

15. Martinez-Gomez D, Eisenmann JC, Tucker J et al. (2011) Associations between moderate-to-vigorous physical activity and central body fat in 3-8-year-old children. Int $J$ Pediatr Obes 6, e611-e614.

16. Chaput JP, Lambert M, Mathieu ME et al. (2012) Physical activity vs. sedentary time: independent associations with adiposity in children. Pediatr Obes 7, 251-258.

17. Vale SMCG, Santos RMR, Soares-Miranda LMDC et al. (2010) Objectively measured physical activity and body mass index in preschool children. Int J Pediatr 2010, 479439.
18. Morano M, Colella D \& Caroli M (2011) Gross motor skill performance in a sample of overweight and non-overweight preschool children. Int J Pediatr Obes 6, 42-46.

19. Lubans DR, Morgan PJ, Cliff DP et al. (2010) Fundamental movement skills in children and adolescents. Sports Med $\mathbf{4 0}$, 1019-1035.

20. Okely AD, Booth ML \& Chey $\mathrm{T}$ (2004) Relationships between body composition and fundamental movement skills among children and adolescents. Res Q Exerc Sport 75, 238-247.

21. Truter L, Pienaar AE \& Toit Du D (2012) The relationship of overweight and obesity to the motor performance of children living in South Africa. S Afr Fam Pract J 54, 429-435.

22. Barnett LM, Lai SK, Veldman SLC et al. (2016) Correlates of gross motor competence in children and adolescents: a systematic review and meta-analysis. Sports Med 46, $1663-1688$.

23. Draper CE, Tomaz SA, Stone M et al. (2017) Developing intervention strategies to optimise body composition in early childhood in South Africa. Biomed Res Int 2017, 5283457.

24. Kimani-Murage EW, Kahn K, Pettifor JM et al. (2010) The prevalence of stunting, overweight and obesity, and metabolic disease risk in rural South African children. BMC Public Health 10, 158.

25. Collinson MA, Tollman SM, Kahn K et al. (2006) Highly prevalent circular migration: households, mobility and economic status in rural South Africa. In Africa on the Move: African Migration and Urbanisation in Comparative Perspective, pp. 194-216 [M Tienda, SE Findley, S Tollman et al., editors]. Johannesburg: Wits University Press.

26. Kahn K, Collinson MA, Gómez-Olivé FX et al. (2012) Profile: Agincourt health and socio-demographic surveillance system. Int J Epidemiol 41, 988-1001.

27. Cole TJ \& Lobstein T (2012) Extended international (IOTF) body mass index cut-offs for thinness, overweight and obesity. Pediatr Obes 7, 284-294.

28. Hinkley T, O'Connell E, Okely AD et al. (2012) Assessing volume of accelerometry data for reliability in preschool children. Med Sci Sports Exerc 44, 2436-2441.

29. Cliff DP, Reilly JJ \& Okely AD (2009) Methodological considerations in using accelerometers to assess habitual physical activity in children aged 0-5 years. J Sci Med Sport 12, $557-567$.

30. Janssen X, Basterfield L, Parkinson KN et al. (2015) Objective measurement of sedentary behavior: impact of nonwear time rules on changes in sedentary time. BMC Public Health 15, 504.

31. Evenson KR, Catellier DJ, Gill K et al. (2008) Calibration of two objective measures of physical activity for children. J Sports Sci 26, 1557-1565.

32. Janssen X, Cliff DP, Reilly JJ et al. (2013) Predictive validity and classification accuracy of ActiGraph energy expenditure equations and cut-points in young children. PLoS One $\mathbf{8}$, e79124.

33. Ulrich DA (2000) Test of Gross Motor Development - 2. Austin, TX: PRO-ED.

34. Cliff DP, Okely AD, Morgan PJ et al. (2012) Proficiency deficiency: mastery of fundamental movement skills and skill components in overweight and obese children. Obesity (Silver Spring) 20, 1024-1033.

35. Barnhart HX, Haber M \& Song J (2002) Overall concordance correlation coefficient for evaluating agreement among multiple observers. Biometrics 58, 1020-1027.

36. Howard SJ, Cook CJ, Mohamed RS et al. (2016) The (possibly negative) effects of physical activity on executive functions: implications of the changing metabolic costs of brain development. J Phys Act Health 13, 1017-1022. 
37. Abrahams Z, Mchiza Z \& Steyn NP (2011) Diet and mortality rates in Sub-Saharan Africa: stages in the nutrition transition. BMC Public Health 11, 801.

38. Sedibe MH, Feeley AB, Voorend C et al. (2014) Narratives of urban female adolescents in South Africa: dietary and physical activity practices in an obesogenic environment. $S$ Afr J Clin Nutr 27, 114-119.

39. Mayosi BM, Flisher AJ, Lalloo UG et al. (2009) The burden of non-communicable diseases in South Africa. Lancet 374, 934-947.

40. Steyn NP, Nel J, Labadarios D et al. (2014) Which dietary diversity indicator is best to assess micronutrient adequacy in children 1 to 9 y? Nutrition 30, 55-60.
41. Naicker N, Mathee A \& Teare J (2015) Food insecurity in households in informal settlements in urban South Africa. $S$ Afr Med J 105, 268-270.

42. Jones S, Hendricks S \& Draper CE (2014) Assessment of physical activity and sedentary behavior at preschools in Cape Town, South Africa. Child Obes 10, 501-510.

43. Kuhl ES, Clifford LM \& Stark LJ (2012) Obesity in preschoolers: behavioral correlates and directions for treatment. Obesity (Silver Spring) 20, 3-29.

44. Prioreschi A, Wrottesley S, Draper CE et al. (2017) Maternal and early life nutrition and physical activity: setting the research and intervention agenda for addressing the double burden of malnutrition in South African children. Glob Health Action 10, 1301085. 